
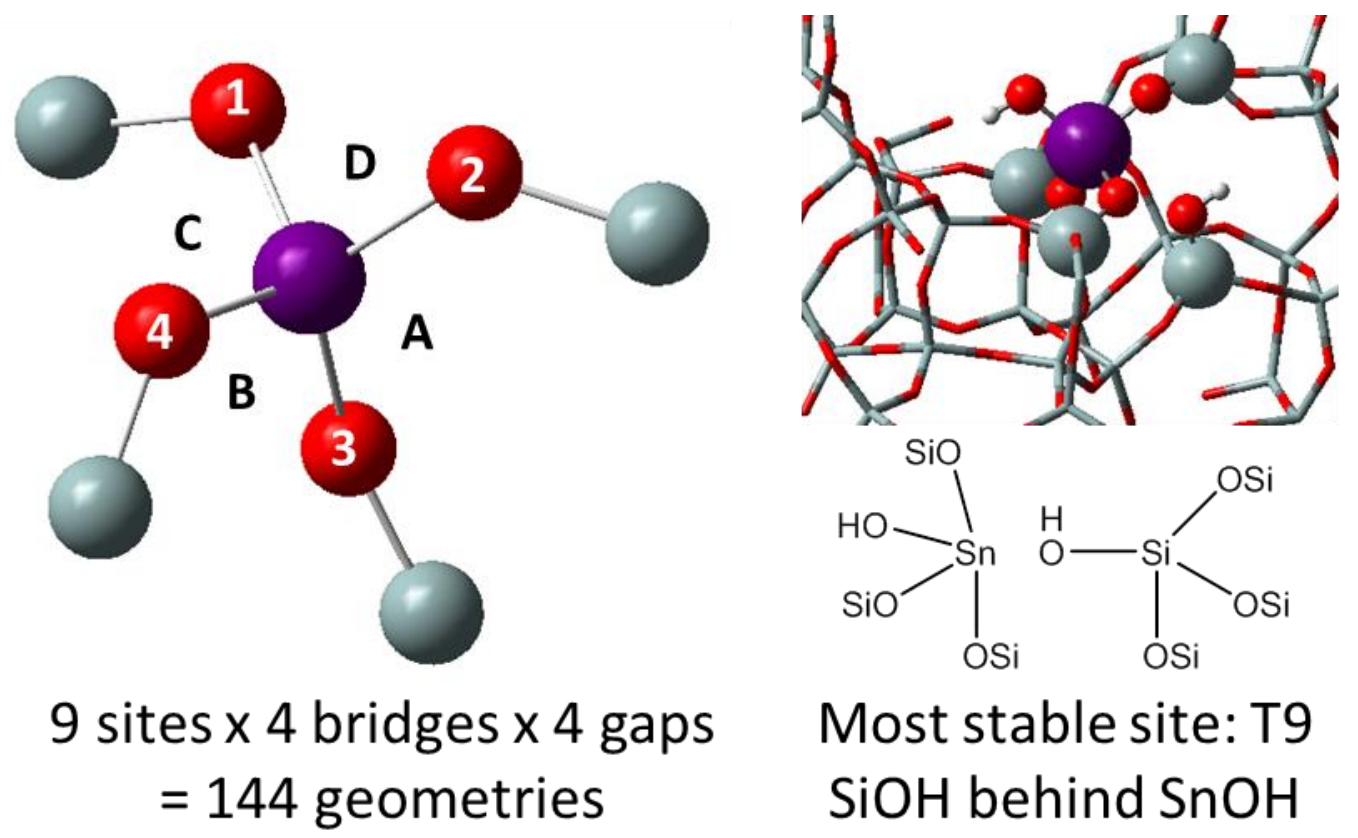

Most stable site: T9

$\mathrm{SiOH}$ behind $\mathrm{SnOH}$

Original resolution:

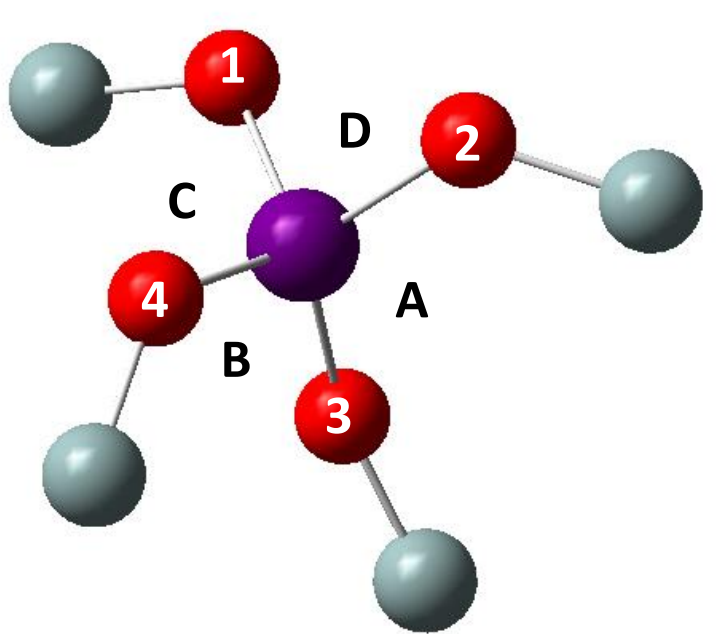

9 sites $x 4$ bridges $x 4$ gaps $=144$ geometries

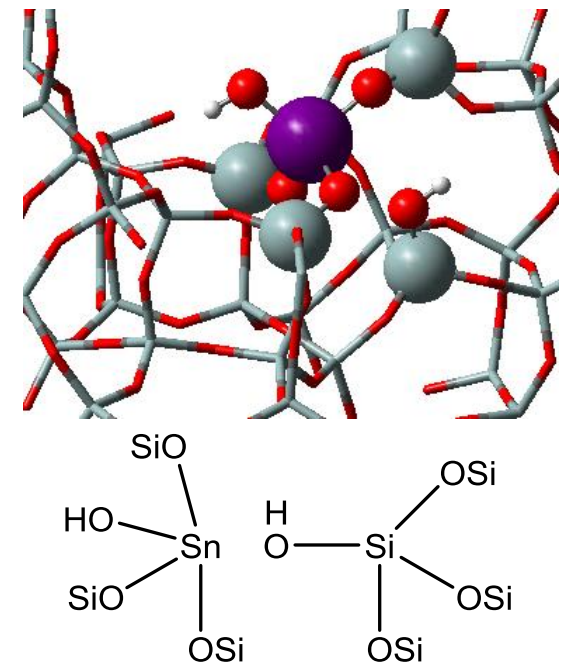

Most stable site: T9 $\mathrm{SiOH}$ behind $\mathrm{SnOH}$ 


\section{Distribution of Open Sites in Sn-Beta Zeolite}

Tyler R. Josephson ${ }^{a}$, Glen R. Jenness ${ }^{a}$, Dionisios G. Vlachos ${ }^{a}$, Stavros Caratzoulas ${ }^{a *}$

\section{ABSTRACT}

A survey of the open site geometries in Sn-Beta has been completed. Comparing the relative energies of 144 distinct open site structures identifies both T9 and T1 sites as the most stable open sites. However, a key feature of these sites is that the Sn-O-Si bridge which is hydrolyzed is opposite the $\mathrm{SnOH}$, rather than adjacent. This results in geometries in which the $\mathrm{SiOH}$ in the open site is significantly more acidic than a surface $\mathrm{SiOH}$ or a $\mathrm{SiOH}$ defect in the zeolite, as found in adsorption calculations of $\mathrm{NH}_{3}$, pyridine, and acetonitrile. Frequency shifts calculated for acetonitrile are consistent with experimental frequency shifts, and the proposed open site geometry suggests a new assignment for a peak observed experimentally by Harris, et al.[1] and Otomo, et al.[2] The stabilization of the open site silanol by the nearby Sn generates this unusual Brønsted acidity in the Sn-Beta open site, which highlights the need to consider new reaction mechanisms in the Sn-Beta literature.

Keywords: Sn-Beta zeolite; periodic DFT; adsorption; $\mathrm{NH}_{3}$; pyridine; acetonitrile

\section{INTRODUCTION}

Sn-substituted zeolites have found applications in a wide range of carbonyl-activating chemistries, including Baeyer-Villiger oxidation of ketones to lactones[3], Meerwein-Ponndorf-Verley (MPV) reduction of carbonyls[4], 1,2-H-shift of glucose[5] and xylose[6], retro-aldol and esterification of sugars to lactates[7,8], the 1,2-carbon shift of glucose[9] and arabinose[10], dehydration reactions in the production of renewable aromatics from furans[11], and the catalytic transfer hydrogenation and etherification of 5-hydroxymethylfurfural[12]. Sn-Beta is particularly relevant for converting biomass 
derivatives derived from sugars $-C_{5}$ and $C_{6}$ compounds that are accommodated by its 12 -member ring pores.

Several techniques have been employed to characterize the structure, activity, and selectivity of the active sites in Sn-Beta. Experiments with ${ }^{119}$ Sn NMR on isotopically-enriched catalysts identified two distinct $\mathrm{Sn}$ sites: the closed site $\mathrm{Sn}(\mathrm{OSi})_{4}$ and a hydrolyzed open site $\mathrm{Sn}(\mathrm{OSi})_{3} \mathrm{OH} .[3,13,14]$ Infrared spectroscopy of adsorbed $\mathrm{CD}_{3} \mathrm{CN}$ has been used to quantify the relative amounts of open and closed sites $[1,2,14,15]$. Boronat, et al. identified a correlation between the amount of $\mathrm{CD}_{3} C N$ adsorbed to open sites in different Sn-Beta samples and the zeolite activity for Baeyer-Villiger Oxidation, providing evidence for open sites as the active sites [15]. Bermejo-Deval, et al. showed that $\mathrm{Na}^{+}$-exchange of SnBeta shifts glucose selectivity from fructose to mannose, shutting down the intramolecular 1,2-H-shift and activating the intramolecular 1,2-C-shift. In addition, $\mathrm{NH}_{3}$ adsorption shuts down catalyst activity by blocking open sites.[14] Otomo, et al. identified weak Brønsted acidic silanols in Sn-Beta using IR spectroscopy of adsorbed $\mathrm{CD}_{3} \mathrm{CN}$, and showed that $\mathrm{Li}^{+}-$, $\mathrm{Na}^{+}-$, and $\mathrm{NH}_{4}{ }^{+}$-exchange passivates these silanols and reduces side reactions in Baeyer-Villiger Oxidation.[2] Recently, Harris, et al. demonstrated the use of pyridine as a selective titrant for these open sites, demonstrating a concomitant reduction in turn-over-frequency for glucose isomerization as open sites are blocked by increasing amounts of pyridine adsorption[1]. Brønsted acids have been hypothesized in Sn-Beta due to its activity in etherification[12], however pyridine adsorption has not given evidence of Brønsted acids in Sn-, Zr-, or Ti-Beta[16,17].

Because individual Sn-Beta active sites are difficult to isolate and test in experiment, the Davis group has synthesized and tested silsesquioxane models of the Sn-Beta active sites[18,19]. These have shown that while the open site model catalysts are significantly more active, the closed site model does have a small amount of glucose isomerization activity. However, the acac ligands present on the open site models stabilize the C-shift reaction [Josephson 2016], and several differences between the 
heterogeneous and homogeneous systems, including solvent and confinement effects, conflated the comparison with Sn-Beta.

To attribute $v(C \equiv N)=2316 \mathrm{~cm}^{-1}$ to the open site, and $v(C \equiv N)=2308 \mathrm{~cm}^{-1}$ to the closed site, Boronat, et al. also performed DFT calculations using cluster models of Sn-Beta with Sn substituted at the $\mathrm{T} 1, \mathrm{~T} 5$, and T9 sites.' Both $\mathrm{T} 5$ and T9 open sites gave comparable $\mathrm{v}(\mathrm{C} \equiv \mathrm{N})$ shifts to experimental $\mathrm{v}(\mathrm{C} \equiv \mathrm{N})$ shifts, and all open sites more strongly bound $\mathrm{CH}_{3} \mathrm{CN}$ than the closed sites[15]. In the same year, Shetty, et al. used periodic-DFT to compare the relative stability of the Sn substitution at all nine T sites, finding $T 2$ to be most stable[20] for closed sites - but open sites were not investigated. Also in the same year, Bare et al. used X-ray absorption fine structure (EXAFS) to characterize Sn-Beta, concluding that Sn is substituted as pairs into the T1 and T2 positions[21]. Since then, a number of theoretical mechanistic studies have used the T2 site[22,23], the T7 site[24,25], or T9 site[26] in investigations of the mechanism for glucose isomerization.

However, no systematic study of the relative stability of Sn-Beta open sites has been performed using periodic-DFT, to enable a comparison of open site stability on equal footing. This communication closes that gap by comparing the energies of 144 distinct Sn-Beta open sites, as well as the binding and spectroscopic features of the most stable sites that are identified.

\section{ELECTRONIC STRUCTURE METHODS}

Periodic density function theory calculations were performed using the GPAW software $[27,28]$ in the ASE framework[29]. The core electrons were represented with the PAW formalism[30,31], while the valence electrons were represented with the Perdew-Burke-Ernzerhof (PBE) exchange-correlation functional[32]. Optimizations were performed using the quasi-Newton limited memory BroydenFletcher-Goldfarb-Shanno (LBFGS) optimizer[33]. Initial optimizations used a double-ろ plus polarization

\footnotetext{
'Note about T site nomenclature: Here, we use the nomenclature originating in the work by Newsam, et al. [36] and Valerio, et al.[38] An alternative nomenclature is used by the International Zeolite Association Structure Commission website. We have included a note in the Supporting Information for clarification.
} 
(DZP) linear combination of atomic orbitals (LCAO) basis set[34], and final optimizations were performed using the finite difference approach with a grid spacing of $0.2 \AA$. Electronic energies were optimized to a precision to $10^{-6} \mathrm{eV}$, with a Fermi-Dirac smearing of $0.1 \mathrm{eV}$, and nuclear degrees of freedom were optimized to a force convergence threshold of $0.05 \mathrm{eV} \AA^{-1}$. Dispersion corrections were estimated using Grimme's DFT-d3 method[35], with structures reoptimized to $0.05 \mathrm{eV} \AA^{-1}$. Frequencies and entropic corrections were calculated using LCAO, after re-optimizing with tighter electronic $\left(10^{-8} \mathrm{eV}\right)$ and force $\left(0.01 \mathrm{eV} \AA^{-1}\right)$ convergence thresholds. All calculations were performed at the $\Gamma$-point.

\section{RESULTS AND DISCUSSION}

\subsection{Relative Stability of Closed Sites}

The geometry of polymorph A of the BEA zeolite framework[36] was obtained from the International Zeolite Association online database[37]. Experimental unit cell parameters $12.632 \times 12.632$ x $26.186 \AA$ were used. Sn atoms were substituted into the framework once at each of the nine T sites, with a Si/Sn ratio of 63 for all structures. The relative stability using PBE and PBE-d3 is reported in Table 1 , in addition to those reported by Shetty, et al.[20]

We find several stable sites for Sn substitution, with T9, T1, and T6 within $1 \mathrm{kcal} / \mathrm{mol}$. In fact, 7 of the sites are within $2.5 \mathrm{kcal} / \mathrm{mol}$ of the most stable T9, suggesting there may be a broad distribution of Sn substitutions at multiple sites. These calculations are considerably different from Shetty, et al., who found T2 and T8 to be relatively stable, but found higher energies (>3 $\mathrm{kcal} / \mathrm{mol}$ ) for the rest of the sites.[20] Differences between these works arise from employing ultrasoft Vanderbilt pseudopotentials instead of the PAW pseudopotentials used in our study.

\subsection{Relative stability of open sites}

The open site of Sn-Beta occurs through the hydrolysis of the closed Sn site, producing a SnOH and a neighboring SiOH. As depicted in Figure 1, the closed Sn site is tetrahedral, with four framework bonds (1-4), and four "gaps" opposite each framework bond (A-D). Binding an OH to one of the "gaps" 
and binding an $\mathrm{H}$ to one of the bridges generates an open site. Each of the nine T sites has four "gaps" and four bridges, generating 144 unique geometries. For the most stable geometries, the $\mathrm{SiOH}$ and $\mathrm{SnOH}$ were rotated and reoptimized to search for the most stable configuration.

The BEA framework has two 12-ring cylindrical channels along the $a$ and $b$ directions, and a helical channel intersecting these along the c direction. Smaller 4, 5, and 6-ring channels also extend through the $a$ and $b$ directions, forming small (4 and 5-ring) and medium (6-ring) pockets between the 12-ring channels. For this study, we have organized the sites according to the location of each "gap" for the $\mathrm{OH}$ in a channel, medium cage, or small cage, and the connectivity of each bridge for the $\mathrm{H}$ (details available in the Supporting Information). In our geometry nomenclature, T1-O12A indicates a Sn at position $\mathrm{T} 1$, with the hydrogen on the oxygen of the T1-T2 bridge, and with the $\mathrm{OH}$ in gap $\mathrm{A}$, a channel according to Table S1.

From this survey, we find the most stable open site to be T9-O29B, depicted in Figure 2 along with a couple less stable alternative geometries (coordinates for these, and all other structures are included as Supporting Information). This site is characterized by a $\mathrm{SnOH}$ protruding into a channel, and the hydrolyzed bridge opposite the $\mathrm{SnOH}$, so the $\mathrm{SiOH}$ oxygen is stabilized by the $\mathrm{Sn}$. In fact, the most stable geometry for each site (highlighted in bold in Table S2), is always characterized in the same waythe $\mathrm{SnOH}$ in a channel and the $\mathrm{SiOH}$ behind the $\mathrm{SnOH}$.

In Figure 3, the full data is plotted against a geometric descriptor: the distance between the oxygen atom of $\mathrm{SnOH}$ and the hydrogen atom of $\mathrm{SiOH}$. This reveals a distinct pattern in the possible geometries: when the $\mathrm{SiOH}$ is behind the $\mathrm{SnOH}$, the $\mathrm{O} \cdots \mathrm{H}$ distance is greater than $4 \AA$; hydrolyzing any of the other three bridges results in a shorter $\mathrm{O} \cdots \mathrm{H}$ distance. Moreover, the relative stability of the longdistance geometries over the short-distance ones is clear by comparing energies of structures within the same T site.

\subsection{Possible formation mechanisms for open site formation}


Sn-Beta synthesis starts from dealuminated H-Beta. Removing aluminum leaves behind silanol "nests," which react with $\mathrm{SnCl}_{4}$ as it is incorporated into the framework. Incomplete condensation of all the silanols could generate open sites. The dynamics of this process are outside the scope of this paper, but one can imagine the possibility of open sites with either "adjacent" or "opposite" configurations after condensation. As we have shown, open sites with the $\mathrm{SiOH}$ adjacent to the $\mathrm{SnOH}$ are typically thermodynamically less stable than those with the $\mathrm{SiOH}$ opposite the $\mathrm{SnOH}$. In some of these cases (but not all), the adjacent $\mathrm{SiOH}$ can transfer its proton to the opposite $\mathrm{Sn}-\mathrm{O}-\mathrm{Si}$ bridge and form the corresponding opposite open site. We tested this for converting T9-O49A (adjacent SiOH) into T9-O29A (opposite $\mathrm{SiOH}$ ) and found the proton transfer to have a negligible barrier $(11 \mathrm{kcal} / \mathrm{mol})$ for relaxing to the more stable open site geometry. Alternatively, water can assist the proton transfer through the Grotthuss mechanism, reducing this already-small barrier to $1 \mathrm{kcal} / \mathrm{mol}$ (Table S3).

Another hypothesized route is through the hydrolysis of closed sites. After adsorption to a closed site, water deprotonates to a Sn-O-Si bridge, forming an "adjacent" open site. Rotation of the H atom about the Si-O bond can then direct it toward the Sn-O-Si bridge that is opposite the $\mathrm{SnOH}$. Transfer of the proton from the SiOH to the bridge could then generate the "opposite" open site. For converting the T9 closed site into T9-029A in the gas phase, we found the overall barrier to be 24.6 $\mathrm{kcal} / \mathrm{mol}$. Details of the reaction are provided in Table S3 in the Supporting Information.

\subsection{Adsorption of Lewis Bases}

Adsorption energies of the Lewis bases $\mathrm{NH}_{3}$, pyridine, and acetonitrile were also calculated for the most stable closed (T9) and open site (T9-O29B) geometries (Table 2 and Figure 4). Because the Sn site is at the intersection of two channels, adsorbates can coordinate to two locations on the Sn closed and open sites, as well as to the $\mathrm{SnOH}$ and the $\mathrm{SiOH}$ for the open site. Different features of the active sites strongly affect adsorption behavior. For all systems, with the exception of $\mathrm{NH}_{3}$ with PBE-d3, the open site binds $2.5-8 \mathrm{kcal} / \mathrm{mol}$ more strongly than the closed site, in agreement with prior work[15]. 
Acetonitrile binds more weakly to the sites than $\mathrm{NH}_{3}$ and pyridine. It binds most strongly to the Sn Lewis acid of the open site, binding $2-4 \mathrm{kcal} / \mathrm{mol}$ more weakly to the $\mathrm{Sn}$ closed site or to the $\mathrm{SnOH}$ or $\mathrm{SiOH}$. For the stronger bases, $\mathrm{NH}_{3}$ and pyridine, the $\mathrm{SnOH}$ is weakly binding, while the $\mathrm{Sn}$ Lewis acid binds comparably to the SiOH; for PBE, the Sn Lewis acid binds $2-3 \mathrm{kcal} / \mathrm{mol}$ more strongly that the $\mathrm{SiOH}$, while for PBE-d3, the SiOH binds $1-2 \mathrm{kcal} / \mathrm{mol}$ more strongly than the $\mathrm{Sn}$ Lewis acid. IR spectroscopy of Sn-Beta with adsorbed pyridine has not shown evidence of pyridinium, possibly indicating that pyridine adsorption to the Lewis site is favored over adsorption to the $\mathrm{SiOH}$, in agreement with the PBE binding energies, but not the PBE-d3.[17]

Adsorption geometries (PBE) are shown in Figure 4. These highlight the unusually acidic nature of the $\mathrm{SiOH}$ in the $\mathrm{Sn}$-Beta open site. For $\mathrm{NH}_{3}$ and pyridine, the SiOH deprotonates to the adsorbate, and the SiO binds to the $\mathrm{Sn}$. In the open site, the $\mathrm{Sn---O}(\mathrm{H})$ Si distance is $3.23 \AA$, while the SiO---H distance is $0.98 \AA$. When $\mathrm{NH}_{3}$ or pyridine bind to the $\mathrm{SiOH}$, the Sn---OSi distances shrinks to $2.16 \AA$ and $2.14 \AA$, respectively, and the SiO---H distance increases to 1.60 and $1.80 \AA$, respectively. Acetonitrile does not abstract the proton, leaving the SiO---H distance at $1.02 \AA$, but the $\mathrm{Sn---O}(\mathrm{H}) \mathrm{Si}$ distance still decreases to $2.48 \AA$, indicating some stabilization of the $\mathrm{SiOH}$ by the $\mathrm{Sn}$.

\subsection{Acetonitrile Vibrations}

We calculated vibrational frequencies for adsorbed acetonitrile to compare with prior work. The $\mathrm{v}(\mathrm{C} \equiv \mathrm{N})$ frequency blueshifts as acetonitrile binds to the catalyst, and it shifts by $35.5 \mathrm{~cm}^{-1}$ on the closed Sn site, and $41.2 \mathrm{~cm}^{-1}$ on the open Sn site, the same trend observed in cluster models of closed and open sites,[15] and in agreement with experimental shifts of the peaks assigned to these two types of Lewis sites. $[1,14,15]$

Acetonitrile can also bind to the $\mathrm{SnOH}$ and the $\mathrm{SiOH}$ in the open site. Adsorption to the $\mathrm{SnOH}$ shifts $v(C \equiv N)$ by $13 \mathrm{~cm}^{-1}$, while adsorption to the SiOH shifts $v(C \equiv N)$ significantly more; by $29.6 \mathrm{~cm}^{-1}$. To compare this to $\mathrm{SiOH}$ defects and surface $\mathrm{SiOH}$, we created a SiOH defect in the Sn-Beta framework by 
replacing the $\mathrm{Sn}$ in the open site with a $\mathrm{Si}$, and also by removing the $\mathrm{Sn}$ atom. Acetonitrile binds less strongly to these $\mathrm{SiOH}$ groups, with $\mathrm{v}(\mathrm{C} \equiv \mathrm{N})$ shifting by an average of $18.2 \mathrm{~cm}^{-1}$. The trend in these shifts on these typical $\mathrm{SiOH}$ groups is consistent with experimental $\mathrm{v}(\mathrm{C} \equiv \mathrm{N})$ shift of $10 \mathrm{~cm}^{-1}$, as well as calculated $v(\mathrm{C} \equiv \mathrm{N})$ shift for a bare $\mathrm{SiOH}$ cluster.[15] Boronat, et al. found the calculated frequency for $\mathrm{SnOH}$ binding to be comparable to that of $\mathrm{SiOH}$, in agreement with our calculated $\mathrm{v}(\mathrm{C} \equiv \mathrm{N})$ shift on the $\mathrm{SnOH}$. However, the open site $\mathrm{SiOH}$ next to the $\mathrm{Sn}$ is significantly more acidic, with a dramatically stronger $\mathrm{v}(\mathrm{C} \equiv \mathrm{N})$ compared to a surface $\mathrm{SiOH}$, indicative of its unique character because of its interaction with the Sn. This Brønsted acidity, arising from the $\mathrm{Sn---O}(\mathrm{H}) \mathrm{Si}$ interaction in the hydrolyzed open site, is consistent with experimental IR spectroscopy of adsorbed $\mathrm{CD}_{3} \mathrm{CN}[1,2]$, and with observations of etherification activity in Sn-Beta[12].

\section{CONCLUSIONS}

Using periodic DFT, we have completed a survey of open site geometries in the Sn-Beta zeolite. At every $\mathrm{T}$ site, the most stable geometry is characterized by a $\mathrm{SnOH}$ protruding into a channel, and an $\mathrm{SiOH}$ behind the $\mathrm{SnOH}$. The most stable site is the T9, although several T sites have energies within 2 $\mathrm{kcal} / \mathrm{mol}$ of the most stable geometry. Adsorption of strong bases such as $\mathrm{NH}_{3}$ and pyridine is favored at the open Sn Lewis site; however adsorption to the SiOH has comparable binding strength to the Lewis site, and resulted into abstraction of the SiOH proton. Calculated frequency shifts of acetonitrile are in agreement with prior experimental and theoretical work. The primary finding is evidence for unusual Brønsted acidity in the Sn-Beta open site, which may enable new reaction mechanisms not yet considered in the literature.

\section{ACKNOWLEDGEMENTS}

Research was supported as part of the Catalysis Center for Energy Innovation, an Energy Frontier Research Center funded by the U.S. Department of Energy (DOE), Office of Science, Basic Energy Sciences (BES), under Award number DE-SC0001004. This research used resources of the 
National Energy Research Scientific Computing Center, a DOE Office of Science User Facility supported by the Office of Science of the U.S. Department of Energy under Contract No. DE-AC02-05CH11231. T.R.J. wishes to acknowledge funding from the National Science Foundation Graduate Research Fellowship Program under Grant No. 0750966, as well as the George W. Laird Merit Fellowship. Any opinions, findings, and conclusions or recommendations expressed in this material are those of the author(s) and do not necessarily reflect the views of the National Science Foundation. The authors would like to thank Zhiqiang Zhang for numerous useful conversations.

\section{REFERENCES}

[1] J.W. Harris, M.J. Cordon, J.R. Di lorio, J.C. Vega-Vila, F.H. Ribeiro, R. Gounder, J. Catal. 335 (2016) 141-154.

[2] R. Otomo, R. Kosugi, Y. Kamiya, T. Tatsumi, T. Yokoi, Catal. Sci. Technol. 6 (2016) 2787-2795.

[3] A. Corma, L.T. Nemeth, M. Renz, S. Valencia, Nature 412 (2001) 423-425.

[4] A. Corma, M.E. Domine, L. Nemeth, S. Valencia, J. Am. Chem. Soc. 124 (2002) 3194-3195.

[5] M. Moliner, Y. Roman-Leshkov, M.E.E. Davis, Y. Román-Leshkov, M.E.E. Davis, Proc Natl Acad Sci U S A 107 (2010) 6164-6168.

[6] V. Choudhary, A.B. Pinar, S.I. Sandler, D.G. Vlachos, R.F. Lobo, ACS Catal. 1 (2011) 1724-1728.

[7] M.S. Holm, S. Saravanamurugan, E. Taarning, Science 328 (2010) 602-605.

[8] M. Orazov, M.E. Davis, Proc. Natl. Acad. Sci. 112 (2015) 201516466.

[9] R. Bermejo-Deval, R. Gounder, M.E. Davis, ACS Catal. 2 (2012) 2705-2713.

[10] W.R. Gunther, Y. Wang, Y. Ji, V.K. Michaelis, S.T. Hunt, R.G. Griffin, Y. Román-Leshkov, Nat. Commun. 3 (2012) 1109.

[11] C.L. Williams, C.-C. Chang, P. Do, N. Nikbin, S. Caratzoulas, D.G. Vlachos, R.F. Lobo, W. Fan, P.J. Dauenhauer, ACS Catal. 2 (2012) 935-939.

[12] J.D. Lewis, S. Van De Vyver, A.J. Crisci, W.R. Gunther, V.K. Michaelis, R.G. Griffin, Y. Román- 
Leshkov, ChemSusChem 7 (2014) 2255-2265.

[13] R. Bermejo-Deval, R.S.S. Assary, E. Nikolla, M. Moliner, Y. Román-Leshkov, S.-J.S.-J. Hwang, A. Palsdottir, D. Silverman, R.F.F. Lobo, L. a. a. Curtiss, M.E.E. Davis, Y. Roman-Leshkov, S.-J.S.-J. Hwang, A. Palsdottir, D. Silverman, R.F.F. Lobo, L. a. a. Curtiss, M.E.E. Davis, Proc. Natl. Acad. Sci. 109 (2012) 9727-9732.

[14] R. Bermejo-Deval, M. Orazov, R. Gounder, S.J. Hwang, M.E. Davis, ACS Catal. 4 (2014) 2288-2297.

[15] M. Boronat, P. Concepción, A. Corma, M. Renz, S. Valencia, J. Catal. 234 (2005) 111-118.

[16] Y. Zhu, G.K. Chuah, S. Jaenicke, J. Catal. 241 (2006) 25-33.

[17] B. Tang, W. Dai, G. Wu, N. Guan, L. Li, M. Hunger, ACS Catal. 4 (2014) 2801-2810.

[18] S.K. Brand, J.A. Labinger, M.E. Davis, ChemCatChem 8 (2016) 121-124.

[19] S.K. Brand, T.R. Josephson, J.A. Labinger, S. Caratzoulas, D.G. Vlachos, M.E. Davis, J. Catal. 341 (2016) 62-71.

[20] S. Shetty, S. Pal, D.G. Kanhere, A. Goursot, Chem. - A Eur. J. 12 (2005) 518-523.

[21] S.R. Bare, S.D. Kelly, W. Sinkler, J.J. Low, S. Valencia, A. Corma, L.T. Nemeth, F.S. Modica, S. Valencia, A. Corma, L.T. Nemeth, J. Am. Chem. Soc. 127 (2005) 12924-12932.

[22] G. Yang, E. a. Pidko, E.J.M. Hensen, ChemSusChem 6 (2013) 1688-1696.

[23] Y.P.P. Li, M. Head-Gordon, A.T.T. Bell, ACS Catal. 4 (2014) 1537-1545.

[24] T.D. Courtney, C.-C. Chang, R.J. Gorte, R.F. Lobo, W. Fan, V. Nikolakis, Microporous Mesoporous Mater. 210 (2015) 69-76.

[25] J.R. Christianson, S. Caratzoulas, D.G. Vlachos, ACS Catal. 5 (2015) 5256-5263.

[26] N. Rai, S. Caratzoulas, D.G. Vlachos, ACS Catal. 3 (2013) 2294-2298.

[27] J. Mortensen, L. Hansen, K. Jacobsen, Phys. Rev. B 71 (2005) 35109.

[28] J. Enkovaara, C. Rostgaard, J.J. Mortensen, J. Chen, M. Dułak, L. Ferrighi, J. Gavnholt, C. Glinsvad, V. Haikola, H. a Hansen, H.H. Kristoffersen, M. Kuisma, a H. Larsen, L. Lehtovaara, M. Ljungberg, 
O. Lopez-Acevedo, P.G. Moses, J. Ojanen, T. Olsen, V. Petzold, N. a Romero, J. Stausholm-Møller, M. Strange, G. a Tritsaris, M. Vanin, M. Walter, B. Hammer, H. Häkkinen, G.K.H. Madsen, R.M. Nieminen, J.K. Nørskov, M. Puska, T.T. Rantala, J. Schiøtz, K.S. Thygesen, K.W. Jacobsen, J. Phys. Condens. Matter 22 (2010) 253202.

[29] S.R. Bahn, K.W. Jacobsen, Comput. Sci. Eng. 4 (2002) 56-66.

[30] P.E. Blöchl, Phys. Rev. B 50 (1994) 17953-17979.

[31] G. Kresse, Phys. Rev. B 59 (1999) 1758-1775.

[32] J.P. Perdew, K. Burke, M. Ernzerhof, Phys. Rev. Lett. 77 (1996) 3865-3868.

[33] D.C. Liu, J. Nocedal, Math. Program. B 45 (1989) 503-528.

[34] A.H. Larsen, M. Vanin, J.J. Mortensen, K.S. Thygesen, K.W. Jacobsen, Phys. Rev. B - Condens. Matter Mater. Phys. 80 (2009) 1-10.

[35] S. Grimme, J. Antony, S. Ehrlich, H. Krieg, J. Chem. Phys. 132 (2010).

[36] J.M. Newsam, M.M.J. Treacy, W.T. Koetsier, C.B. de Gruyter, Proc R Soc L. A 420 (1988) 375-405.

[37] C. Baerlocher, L.B. McCusker, Database of Zeolite Structures: http://www.izastructure.org/databases/.

[38] G. Valerio, a Goursot, R. Vetrivel, O. Malkina, V. Malkin, D.R. Salahub, J. Am. Chem. Soc. 120 (1998) 11426-11431. 
Table 1. Relative stability of closed Sn-Beta sites

\begin{tabular}{|c|c|c|c|}
\hline & $\begin{array}{c}\Delta \mathrm{E}, \mathrm{PBE}, \\
\mathrm{kcal} / \mathrm{mol}\end{array}$ & $\begin{array}{c}\Delta \mathrm{E}, \mathrm{PBE}-\mathrm{d} 3, \\
\mathrm{kcal} / \mathrm{mol}\end{array}$ & $\begin{array}{c}\Delta \mathrm{E} \text { from Shetty, } \\
\text { et al.[20] } \\
(\mathrm{kcal} / \mathrm{mol})\end{array}$ \\
\hline $\mathrm{T} 1$ & 0.459 & 1.074 & 6.762 \\
\hline $\mathrm{T} 2$ & 2.198 & 2.767 & 0 \\
\hline $\mathrm{T} 3$ & 1.386 & 1.347 & 4.899 \\
\hline $\mathrm{T} 4$ & 1.761 & 2.162 & 3.634 \\
\hline T5 & 4.013 & 4.338 & 6.348 \\
\hline T6 & 0.866 & 1.172 & 5.750 \\
\hline T7 & 2.802 & 3.086 & 5.152 \\
\hline T8 & 2.273 & 1.876 & 1.380 \\
\hline T9 & 0 & 0 & 8.234 \\
\hline
\end{tabular}


Table 2. Binding energies in $\mathrm{kcal} / \mathrm{mol}$ calculated with PBE for various bases on the $\mathrm{Sn}$ sites, with gas phase adsorbate and bare catalyst as reference.

\begin{tabular}{|c|c|c|c|c|c|c|}
\hline PBE $\Delta E$ & Closed Sn 1 & Closed Sn 2 & Open Sn 1 & Open Sn 2 & SnOH & SiOH \\
\hline Acetonitrile & -7.00 & -6.98 & -9.56 & -10.43 & -8.55 & -6.13 \\
NH3 & -15.54 & -16.11 & -15.72 & -18.49 & -10.36 & -15.45 \\
Pyridine & -12.47 & -12.06 & -13.90 & -20.91 & -9.12 & -18.40 \\
\hline
\end{tabular}

\begin{tabular}{|c|c|c|c|c|c|c|}
\hline PBE-d3 $\Delta \mathrm{E}$ & Closed Sn 1 & Closed Sn 2 & Open Sn 1 & Open Sn 2 & SnOH & SiOH \\
\hline Acetonitrile & -15.98 & -16.01 & -17.39 & -16.01 & -14.33 & -14.40 \\
NH3 & -21.46 & -22.20 & -21.09 & -21.85 & -13.82 & -22.24 \\
Pyridine & -27.73 & -27.36 & -29.21 & -32.35 & -22.41 & -34.34 \\
\hline
\end{tabular}

\begin{tabular}{|c|c|c|c|c|c|c|}
\hline PBE $\Delta \mathrm{G}$ & Closed Sn 1 & Closed Sn 2 & Open Sn 1 & Open Sn 2 & SnOH & SiOH \\
\hline Acetonitrile & 6.33 & & 1.01 & -2.55 & 0.08 & 4.13 \\
\hline
\end{tabular}


Table 3. Vibrational frequencies of acetonitrile adsorbed onto different Sn sites, and comparison with literature. * Harris, et al.[1] assigned this frequency to a speculated doublyhydrolyzed Sn site and Otomo, et al.[2] observed this peak, but did not assign it; we list it here with our proposed assignment.

\begin{tabular}{|c|c|c|c|c|c|c|c|}
\hline & $\begin{array}{l}\text { Closed } \\
\text { Sn }\end{array}$ & Open Sn & $\begin{array}{c}\text { Open Sn } \\
\text { SiOH (acidic) }\end{array}$ & $\begin{array}{l}\text { Open Sn } \\
\text { SiOH }\end{array}$ & $\mathrm{SnOH}$ & $\mathrm{SiOH}$ & $\begin{array}{c}\text { Gas } \\
\text { Phase }\end{array}$ \\
\hline Calc. $v(C \equiv N)\left(\mathrm{cm}^{-1}\right)$ & 2281.9 & 2287.6 & 2278.2 & 2261.7 & 2261.6 & 2266.8 & 2248.6 \\
\hline$\Delta v(C \equiv N)\left(\mathrm{cm}^{-1}\right)$ & 33.3 & 39 & 29.6 & 13.1 & 13.0 & 18.2 & 0 \\
\hline Exp.[15] v(C=N) $\left(\mathrm{cm}^{-1}\right)$ & 2308 & 2316 & & & & 2276 & 2265 \\
\hline$\Delta v(C \equiv N)\left(\mathrm{cm}^{-1}\right)$ & 43 & 51 & & & & 11 & 0 \\
\hline $\begin{array}{c}\text { Calc.[15] } \Delta v(C \equiv N)\left(\mathrm{cm}^{-1}\right) \\
\text { Average of } T 1, T 5, T 9\end{array}$ & 43 & 53 & & & 17 & 16 & \\
\hline $\begin{array}{c}\text { Exp.[14] } v(C \equiv N)\left(\mathrm{cm}^{-1}\right) \\
\Delta v(C \equiv N)\left(\mathrm{cm}^{-1}\right)\end{array}$ & 2307 & 2315 & & & & 2276 & \\
\hline $\operatorname{Exp} .[1,2] v(C \equiv N)\left(\mathrm{cm}^{-1}\right)$ & 2308 & 2316 & $2287^{*}$ & & & 2275 & 2265 \\
\hline$\Delta \mathrm{v}(\mathrm{C} \equiv \mathrm{N})\left(\mathrm{cm}^{-1}\right)$ & 43 & 51 & $22 *$ & & & 10 & 0 \\
\hline
\end{tabular}



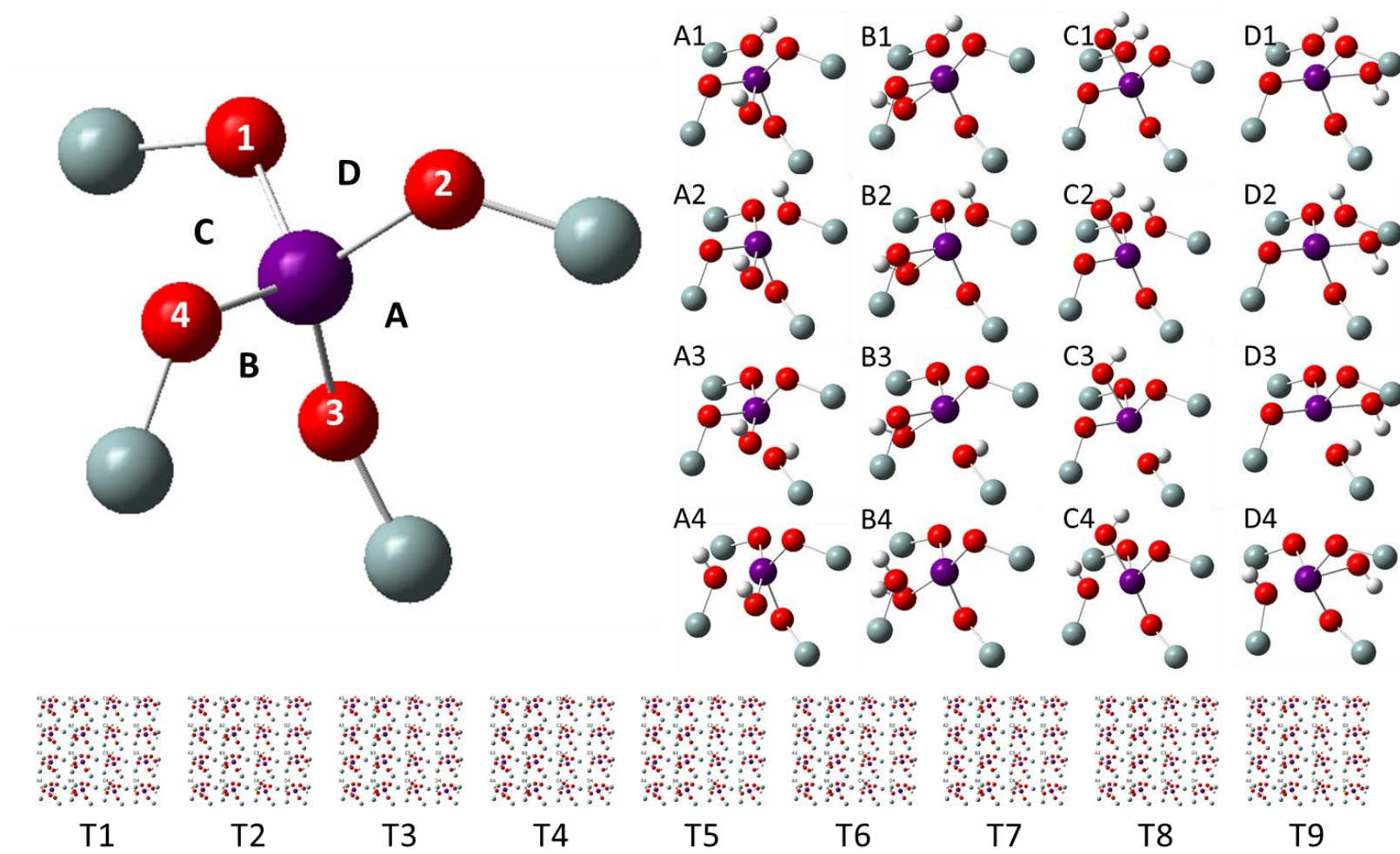

Figure 1 - Diagram depicting tetrahedral Sn site, and four framework bonds (1-4) and four "gaps" opposite each framework bond (A-D). To form an open site, one $\mathrm{H}$ is placed on a framework bond and one $\mathrm{OH}$ is placed in a "gap," providing 16 unique bonding patterns for each T site. Repeating this procedure on all nine T sites generates 144 candidate open sites. 


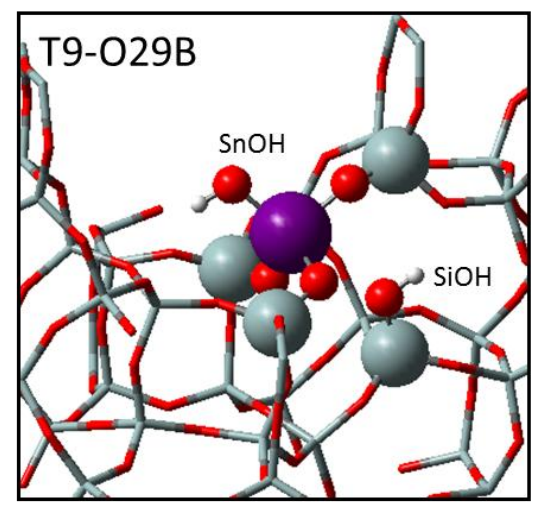

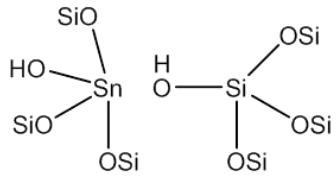

$\mathrm{SiOH}$ behind $\mathrm{SnOH}$ $\mathrm{E}=0.0 \mathrm{kcal} / \mathrm{mol}$
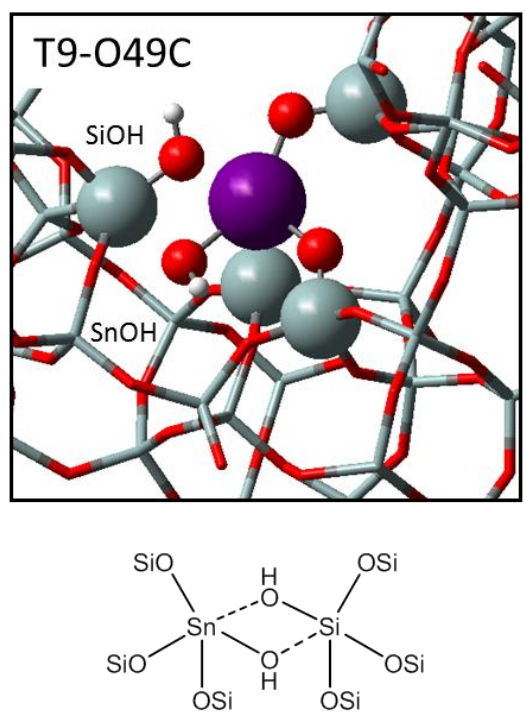

Dibridging

$\mathrm{E}=13.4 \mathrm{kcal} / \mathrm{mol}$
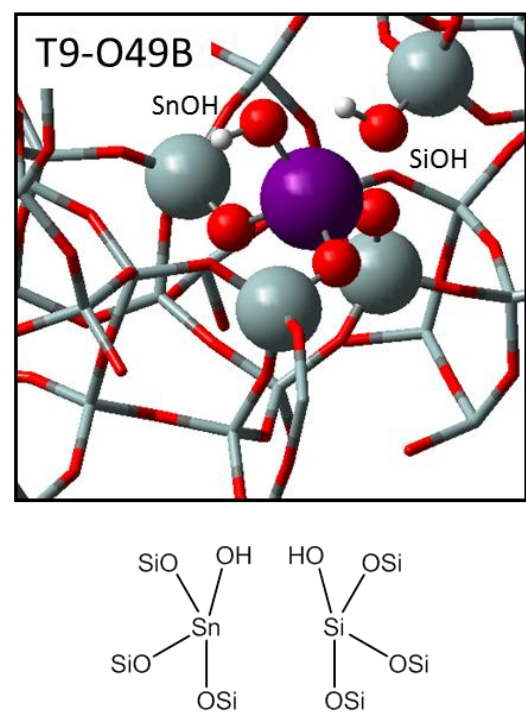

$\mathrm{SiOH}$ adjacent to $\mathrm{SnOH}$ $\mathrm{E}=12.8 \mathrm{kcal} / \mathrm{mol}$

Figure 2 - Selected geometries of different open site configurations. T9-O29B is the most stable open site geometry, and the $\mathrm{SiOH}$ is positioned behind the $\mathrm{SnOH}$. Two additional geometries, T9-O49C and T9-O49B are shown to illustrate examples of less stable dibridging and $\mathrm{H}$-bonded open sites, respectively. Energies are reported with respect to the most stable T9-O29B geometry. 


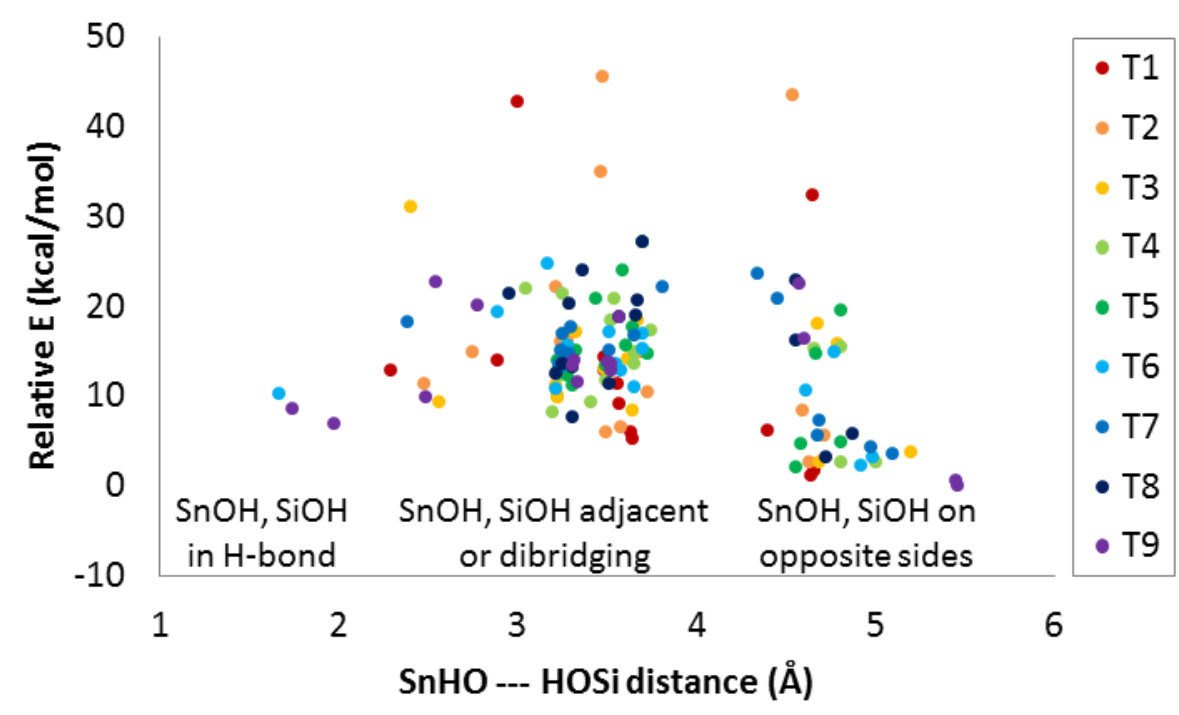

Figure 3 - Relative PBE energy $(\mathrm{kcal} / \mathrm{mol})$ of open sites with respect to the distance between the oxygen of $\mathrm{SnOH}$ and the hydrogen of $\mathrm{SiOH}$. The largest $\mathrm{O}-\mathrm{H}$ distances $(>4 \AA)$ correspond to geometries in which the $\mathrm{SnOH}$ and $\mathrm{SiOH}$ are on opposite sides, the shortest distances $(<2 \AA)$ are approximate $\mathrm{H}$-bonds between $\mathrm{SiOH}$ and $\mathrm{SnOH}$, and the intermediate distances include the other structures, including the dibridging geometries. 


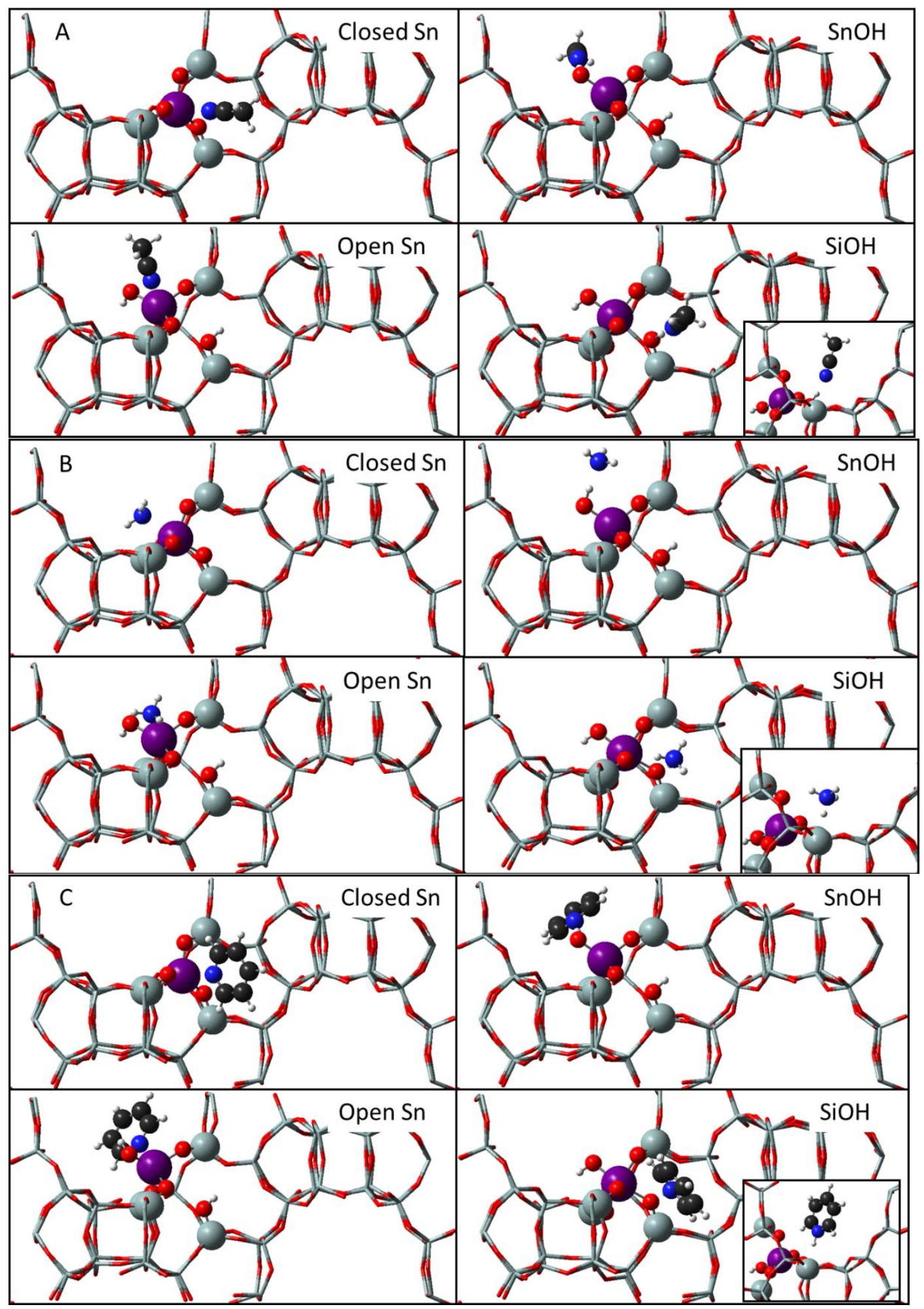

Figure 4 - Most stable adsorption geometries of acetonitrile (A), $\mathrm{NH}_{3}(\mathrm{~B})$, and pyridine (C) on the T8 Sn-Beta closed Sn site, open Sn site, open $\mathrm{SnOH}$, and open $\mathrm{SiOH}$. Inset image shows side view of adsorbate bound to the $\mathrm{SiOH}$. Adsorbates and first coordination shell around $\mathrm{Sn}$ site are depicted using ball-and-stick model, while rest of zeolite framework is depicted using tube model. 
Table 1 - Relative stability of closed Sn-Beta sites

\begin{tabular}{|c|c|c|c|}
\hline & $\begin{array}{c}\Delta \mathrm{E}, \mathrm{PBE}, \\
\mathrm{kcal} / \mathrm{mol}\end{array}$ & $\begin{array}{c}\Delta \mathrm{E}, \mathrm{PBE}-\mathrm{d} 3, \\
\mathrm{kcal} / \mathrm{mol}\end{array}$ & $\begin{array}{c}\Delta \mathrm{E} \text { from Shetty, } \\
\text { et al. [16] } \\
\text { (kcal/mol) }\end{array}$ \\
\hline $\mathrm{T} 1$ & 0.459 & 1.074 & 6.762 \\
\hline $\mathrm{T} 2$ & 2.198 & 2.767 & 0 \\
\hline $\mathrm{T} 3$ & 1.386 & 1.347 & 4.899 \\
\hline $\mathrm{T} 4$ & 1.761 & 2.162 & 3.634 \\
\hline $\mathrm{T} 5$ & 4.013 & 4.338 & 6.348 \\
\hline $\mathrm{T} 6$ & 0.866 & 1.172 & 5.750 \\
\hline $\mathrm{T} 7$ & 2.802 & 3.086 & 5.152 \\
\hline $\mathrm{T} 8$ & 2.273 & 1.876 & 1.380 \\
\hline $\mathrm{T} 9$ & 0 & 0 & 8.234 \\
\hline
\end{tabular}


Table 2 - Binding energies in $\mathrm{kcal} / \mathrm{mol}$ calculated with PBE for various bases on the $\mathrm{Sn}$ sites, with gas phase adsorbate and bare catalyst as reference.

\begin{tabular}{|c|c|c|c|c|c|c|}
\hline PBE $\Delta \mathrm{E}$ & Closed Sn 1 & Closed Sn 2 & Open Sn 1 & Open Sn 2 & SnOH & SiOH \\
\hline Acetonitrile & -7.00 & -6.98 & -9.56 & -10.43 & -8.55 & -6.13 \\
NH3 & -15.54 & -16.11 & -15.72 & -18.49 & -10.36 & -15.45 \\
Pyridine & -12.47 & -12.06 & -13.90 & -20.91 & -9.12 & -18.40 \\
\hline
\end{tabular}

\begin{tabular}{|c|c|c|c|c|c|c|}
\hline PBE-d3 $\Delta \mathrm{E}$ & Closed Sn 1 & Closed Sn 2 & Open Sn 1 & Open Sn 2 & SnOH & SiOH \\
\hline Acetonitrile & -15.98 & -16.01 & -17.39 & -16.01 & -14.33 & -14.40 \\
NH3 & -21.46 & -22.20 & -21.09 & -21.85 & -13.82 & -22.24 \\
Pyridine & -27.73 & -27.36 & -29.21 & -32.35 & -22.41 & -34.34 \\
\hline
\end{tabular}

\begin{tabular}{|c|c|c|c|c|c|c|}
\hline PBE $\Delta \mathrm{G}$ & Closed Sn 1 & Closed Sn 2 & Open Sn 1 & Open Sn 2 & SnOH & SiOH \\
\hline Acetonitrile & 6.33 & & 1.01 & -2.55 & 0.08 & 4.13 \\
\hline
\end{tabular}


Table 3 - Vibrational frequencies of acetonitrile adsorbed onto different Sn sites, and comparison with literature. * Harris, et al.[1] assigned this frequency to a speculated doublyhydrolyzed Sn site; we list it here with our recommended assignment.

\begin{tabular}{|c|c|c|c|c|c|c|c|}
\hline & $\begin{array}{c}\text { Closed } \\
\text { Sn }\end{array}$ & Open Sn & $\begin{array}{c}\text { Open Sn } \\
\text { SiOH (acidic) }\end{array}$ & $\begin{array}{c}\text { Open Sn } \\
\text { SiOH }\end{array}$ & $\mathrm{SnOH}$ & $\mathrm{SiOH}$ & $\begin{array}{c}\text { Gas } \\
\text { Phase }\end{array}$ \\
\hline $\begin{array}{c}\text { Calc. } v(C \equiv N)\left(\mathrm{cm}^{-1}\right) \\
\Delta v(C \equiv N)\left(\mathrm{cm}^{-1}\right)\end{array}$ & $\begin{array}{c}2281.9 \\
33.3\end{array}$ & $\begin{array}{c}2287.6 \\
39\end{array}$ & $\begin{array}{c}2278.2 \\
29.6\end{array}$ & $\begin{array}{c}2261.7 \\
13.1\end{array}$ & $\begin{array}{c}2261.6 \\
13.0\end{array}$ & $\begin{array}{c}2266.8 \\
18.2\end{array}$ & $\begin{array}{c}2248.6 \\
0\end{array}$ \\
\hline $\begin{array}{c}\text { Exp.[13] v(C三N) }\left(\mathrm{cm}^{-1}\right) \\
\Delta v(C \equiv N)\left(\mathrm{cm}^{-1}\right)\end{array}$ & $\begin{array}{c}2308 \\
43\end{array}$ & $\begin{array}{c}2316 \\
51\end{array}$ & & & & $\begin{array}{c}2276 \\
11\end{array}$ & $\begin{array}{c}2265 \\
0 \\
\end{array}$ \\
\hline $\begin{array}{c}\text { Calc.[13] } \Delta v(C \equiv N)\left(\mathrm{cm}^{-1}\right) \\
\text { Average of } T 1, T 5, T 9\end{array}$ & 43 & 53 & & & 17 & 16 & \\
\hline $\begin{array}{c}\text { Exp.[12] } v(C \equiv N)\left(\mathrm{cm}^{-1}\right) \\
\Delta v(C \equiv N)\left(\mathrm{cm}^{-1}\right)\end{array}$ & 2307 & 2315 & & & & 2276 & \\
\hline $\begin{array}{c}\text { Exp.[1] } v(C \equiv N)\left(\mathrm{cm}^{-1}\right) \\
\Delta v(C \equiv N)\left(\mathrm{cm}^{-1}\right)\end{array}$ & $\begin{array}{c}2308 \\
43\end{array}$ & $\begin{array}{c}2316 \\
51\end{array}$ & $\begin{array}{c}2287^{*} \\
22 *\end{array}$ & & & $\begin{array}{c}2275 \\
10\end{array}$ & $\begin{array}{c}2265 \\
0\end{array}$ \\
\hline
\end{tabular}

